\title{
The Comparison of Carotid Artery Intima-media Thickness and Plaque Characteristics between Patients with ST-elevation Myocardial Infarction and Coronary Artery Chronic Total Occlusion
}

\author{
Sun Young Choi and Jong Sung Park ${ }^{\dagger}$ \\ Department of Cardiology, Dong-A University Medical Center, Busan 49201, Korea
}

\begin{abstract}
ST-segment elevation myocardial infarction (STEMI) and chronic total occlusion (CTO) of coronary artery are wellknown atherosclerotic vascular diseases. However, the difference of intima-media thickness and plaque characteristics of carotid arteries between STEMI and CTO patients were not directly compared in previous studies. Medical records of a total of 158 (101 STEMI, 57 CTO) patients, who underwent carotid artery ultrasonography, were selected for the analysis. The baseline characteristics, ultrasonography findings, and clinical outcomes of the two groups were compared. The prevalence of hypertension, diabetes mellitus, and dyslipidemia was significantly higher in CTO patients. Carotid intima-media thickness $(0.97 \pm 0.13$ vs. $0.78 \pm 0.17 \mathrm{~mm}, P<0.0001)$ and number of plaques $(2.2 \pm 1.0$ vs. $1.7 \pm$ $1.2, P<0.0001)$ were greater in CTO than STEMI patients. Multiple $(\geq 3)$ or echogenic plaques were more frequently observed in CTO patients. During the median follow-up duration of 27 months, major adverse cardiovascular events occurred in $31 \%$ of CTO and 14\% of STEMI patients $(P=0.008)$. We found that, compared with STEMI, CTO patients have higher burden of carotid artery atherosclerosis associated with more comorbid diseases and poor clinical outcomes.
\end{abstract}

Key Words: Ultrasonography, Carotid artery, Myocardial infarction

\section{INTRODUCTION}

High resolution ultrasonography of carotid artery provides a noninvasive assessment of atherosclerosis burden (Heiss et al., 1991; Wendelhag et al., 1992; Salonen and Salonen, 1991). Increased intima-media thickness and complex plaque characteristics of carotid arteries are well-known risk factors for cardiovascular or cerebrovascular diseases (O'Leary et al., 1992; Mannami et al., 1997; Bots et al., 1992). Although intima-media thickness and plaque complexity are closely

\footnotetext{
*Received: October 29, 2015 / Accepted: November 13, 2015

${ }^{\dagger}$ Corresponding author: Jong Sung Park. Department of Cardiology, Dong-A University Medical Center, 26 Daesingongwon-ro, Seo-gu, Busan 49201, Korea.

Tel: +82-51-240-5040, Fax: +82-51-242-2059

e-mail: thinkmed@dau.ac.kr

(C) The Korean Society for Biomedical Laboratory Sciences. All rights reserved.
}

related with each other (O'Leary et al., 1992), they reflect different pathological processes and aspects of atherosclerosis progression. Increased intima-media thickness, especially in its early developmental stage, reflects a hypertrophic response of the carotid artery medial cells to high blood pressure (Mannami et al., 1997; Bots et al., 1992) and is generally regarded as a part of the arterial remodeling observed in early stage of atherosclerosis (O'Leary et al., 1996; Amato et al., 2007; Aldridge et al., 2013). In contrast, the presence of arterial plaques represents atherosclerosis in advanced stage (Hegele, 1996), and is regarded as a more powerful predictor of cardiovascular events than intima-media thickness (Spence et al., 2002; Johnsen et al., 2007).

ST-segment elevation myocardial infarction (STEMI) is one of the most fatal cardiac diseases caused by acute rupture of atherosclerotic plaque and thrombotic total occlusion of coronary artery (Tsujita et al., 2010; Dohi et al., 2010). In 

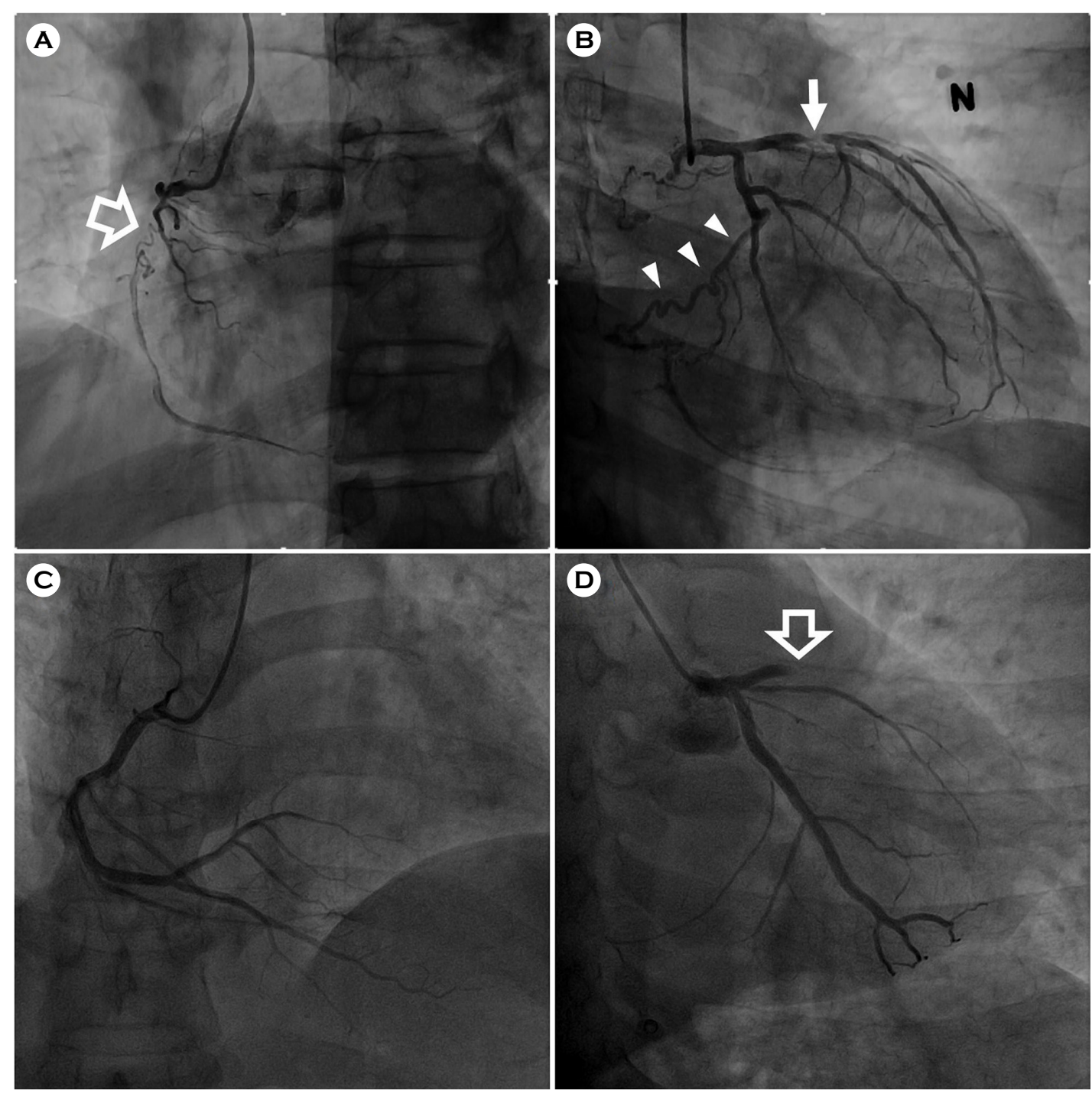

Fig. 1. Coronary artery angiography findings. A 65-year-old male patient visited cardiology outpatient clinic for recurrent squeezing chest pain aggravated during physical activities. (A) Right coronary angiography shows a total occlusion (empty arrow) of the proximal portion of the right coronary artery with a thin tortuous bridging collateral circulation vessel, which is connecting proximal and distal portions of the occluded right coronary artery. (B) Left coronary angiography shows a well-developed collateral circulation vessel (arrowheads) connected to a distal branch or the right coronary artery. A significant narrowing (arrow) of the left anterior descending coronary artery is noted. A 38-year-old male patient visited emergency room for persistent squeezing chest pain. (C) Right coronary angiography shows no significant occlusive lesion or collateral circulation vessel. (D) However, left coronary angiography shows a total occlusion (empty arrow) with abrupt cut-off suggesting the presence of thrombus.

contrast, chronic total occlusion (CTO) of coronary artery is regarded as relatively benign cardiac disease caused by gradual total atherosclerotic obstruction by large burdens of plaques. CTO is characterized by collateral circulation vessels, which mean the presence of significant obstruction over 3 months (Fig. 1). It is well known that pathogenesis and clinical manifestation of the two diseases are different. While STEMI is acute event associated with thrombosis, CTO is a chronic progressive pathologic condition associated with heavy atherosclerotic plaque burden. Coronary artery CTO is differentiated from STEMI clinically by stable symptoms, long standing coronary artery obstruction over 3 months, 
and well developed collateral circulations (Stone et al., 2005). Although STEMI and coronary artery CTO are regarded to be in different stages of atherosclerosis, the differences of carotid artery intima-media thickness and plaque characteristics were not compared directly in previous studies. So we conducted a retrospective analysis to know whether the burden of carotid artery atherosclerosis is different between STEMI and CTO patients.

\section{MATERIALS AND METHODS}

\section{Study population}

All patients were recruited from the coronary artery disease database of Dong-A University Medical Center, Busan, Republic of Korea. Of the patients who underwent diagnostic coronary angiography for STEMI or CTO from 2007 to 2014, those patients undergoing carotid artery ultrasonography were selected for the analysis. Their medical records were reviewed retrospectively. Parameters of clinical characteristics, carotid artery and cardiac ultrasonography, and clinical outcomes were analyzed.

\section{Cardiac and carotid artery ultrasonography measure- ments}

Cardiac ultrasonography was performed using an iE33 ultrasound system and 2.5 MHz transducers (Philips Ultrasound, Andover, MA, USA). Standard M-mode, 2-dimensional, and Doppler echocardiography were routinely performed according to American Society of Echocardiography recommendations. The measurements of carotid intima-media thickness were performed using iE33 ultrasound system and 7.5 MHz real-time B-mode transducers (Philips Ultrasound, Andover, MA, USA). The patients were asked to lie supine with their necks gently extended and rotated laterally slightly. Then, sonographers scanned the carotid artery beneath the surface of the neck. Common carotid artery, bulb, internal and external carotid arteries were examined bilaterally. Carotid intima-medial thickness was defined as the distance from the front edge of the first echogenic line (lumen-intima interface) to the front edge of the second line (media-adventitia interface) on B-mode ultrasonography images (Fig. 2). Carotid intima-media thicknesses were measured at common carotid artery $1 \sim 2 \mathrm{~cm}$ below the bifurcation of bulb bilaterally. The mean intima-media thickness was defined as an average of maximal values measured at both carotid arteries (Su et al., 1999). Carotid artery plaque was defined as a focal vascular structure encroaching into the arterial lumen over at least $0.5 \mathrm{~mm}$ or $50 \%$ of the surrounding intima-media thickness, or as thickened intimamedia thickness greater than $1.2 \mathrm{~mm}$ (Belcaro et al., 1996). Echolucent plaque was defined as a plaque with low echogenicity similar with carotid artery lumen. Echogenic plaque was defined as a plaque with high echogenicity similar with the bright echo zone produced by the media-adventitia interface. Plaques in common carotid artery, bulb, internal and external carotid arteries were assessed bilaterally.

\section{Clinical outcome parameters and definitions}

Major adverse cardiac events were defined as a composite of all causes of death, non-fatal acute myocardial infarction, non-fatal stroke (cerebral or cerebellar infarction, intracranial hemorrhage, and subarachnoid hemorrhage), and repeated revascularization by percutaneous coronary artery intervention or bypass surgery.

\section{Statistical analysis}

Continuous variables are expressed as means \pm standard deviations and were analyzed using Student's $t$-test. Categorical variables were summarized in terms of number and percentages, and were analyzed by using chi-square test or Fisher exact test. Survival data were estimated according to the Kaplan-Meier method, and the differences between two groups were compared with the log-rank test (using MedCalc Version 12.2.1, MedCalc software, Mariakerke, Belgium). A $P$ value $<0.05$ was considered to indicate statistical significance. Statistical analyses were performed using SPSS version 18.0 (SPSS Inc., Chicago, IL, USA).

\section{Ethical review}

The present study protocol was reviewed and approved by the internal review board of Dong-A University Hospital. 

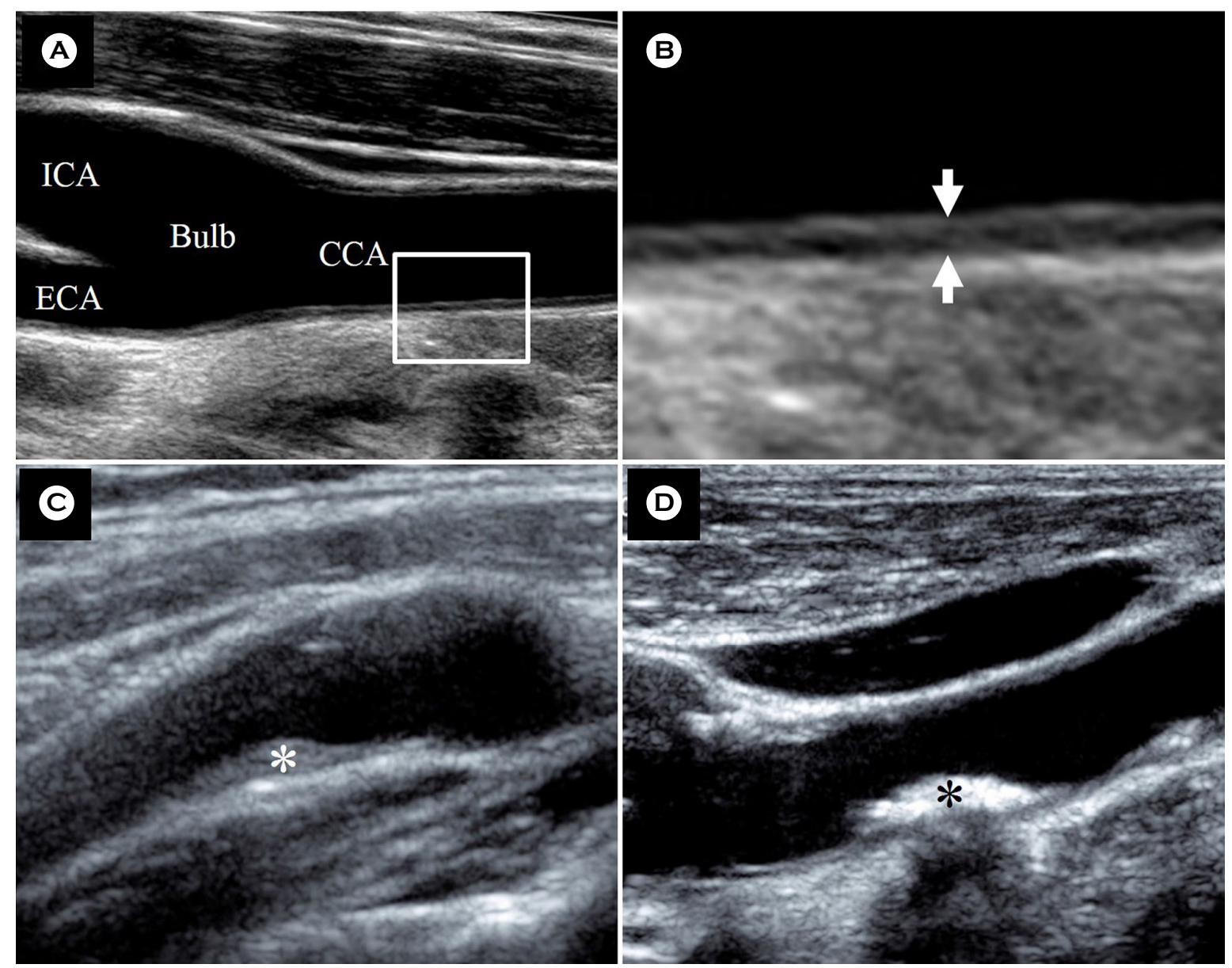

Fig. 2. The measurements and plaque characteristics of carotid artery ultrasonography. (A) Carotid artery ultrasonography shows carotid artery anatomy. Carotid intima-media thicknesses were measured at common carotid artery $1 \sim 2 \mathrm{~cm}$ below the bifurcation of bulb bilaterally. (B) Carotid intima-media thickness was measured the distance from the front edge of the first echogenic line (lumen-intima interface) to the front edge of the second line (media-adventitia interface). (C) The echolucent plaque (white asterisk) is presented in internal carotid artery of STEMI patient. (D) The calcified echogenic plaque (black asterisk) is presented in common carotid artery of CTO patients. ICA, internal carotid artery; ECA, external carotid artery; CCA, common carotid artery.

\section{RESULTS}

\section{Characteristics of the study patients}

Baseline characteristics of the studied patients are summarized in Table 1. Among the screened 603 STEMI and 410 CTO patients, total 158 patients with 101 (64\%) STEMI and 57 (36\%) CTO patients were finally selected for the analysis. Their mean age was $60 \pm 12$ years, and СТO patients were older than those with STEMI patients. 130 $(82 \%)$ of total patients were male. The prevalence of comorbid diseases including hypertension, diabetes mellitus and dyslipidemia was consistently higher in CTO patients. The proportions of patients who were taking anti-platelet agents or statins before angiographic diagnosis of STEMI or CTO were also higher in CTO patients. In the angiography finding, the number of coronary arteries with significant $(>$ $50 \%$ of lumen diameter) stenotic region was greater in CTO than STEMI patients. The systolic blood pressure was also higher in CTO patients. However, the proportion of smoker and low density lipoprotein level were higher in STEMI patients. There were no significant between-group differences 
Table 1. Baseline characteristics of the studied patients

\begin{tabular}{|c|c|c|c|}
\hline Clinical parameters & $\begin{array}{c}\text { STEMI } \\
(\mathrm{n}=101)\end{array}$ & $\begin{array}{c}\text { CTO } \\
(\mathrm{n}=57)\end{array}$ & $P$ \\
\hline Age, years & $59 \pm 12$ & $65 \pm 10$ & 0.001 \\
\hline $20 \sim 39$ years, $\mathrm{n}(\%)$ & $6(6)$ & $0(0)$ & 0.063 \\
\hline $40 \sim 59$ years, $\mathrm{n}(\%)$ & $49(48)$ & $20(34)$ & 0.063 \\
\hline $60 \sim 79$ years, $\mathrm{n}(\%)$ & $45(44)$ & $38(64)$ & 0.009 \\
\hline$>80$ years, $\mathrm{n}(\%)$ & $3(3)$ & $1(2)$ & 0.537 \\
\hline Male sex, n (\%) & $84(83)$ & $46(81)$ & 0.426 \\
\hline Body mass index, $\mathrm{Kg} / \mathrm{m}^{2}$ & $24 \pm 3$ & $25 \pm 3$ & 0.173 \\
\hline Body surface area, $\mathrm{m}^{2}$ & $1.8 \pm 0.2$ & $1.8 \pm 0.2$ & 0.826 \\
\hline Systolic BP, mm Hg & $126 \pm 27$ & $139 \pm 22$ & 0.002 \\
\hline Diastolic BP, mm Hg & $76 \pm 18$ & $77 \pm 13$ & 0.826 \\
\hline \multicolumn{4}{|l|}{ Comorbid diseases } \\
\hline Hypertension, $\mathrm{n}(\%)$ & $46(46)$ & $44(77)$ & $<0.0001$ \\
\hline Diabetes mellitus, n (\%) & $28(28)$ & $25(44)$ & 0.030 \\
\hline Dyslipidemia, $\mathrm{n}(\%)$ & $16(16)$ & $21(37)$ & 0.003 \\
\hline Prior cerebral infarction, $\mathrm{n}(\%)$ & $9(9)$ & $10(18)$ & 0.091 \\
\hline Chronic kidney disease in stage 4 or $5, \mathrm{n}(\%)$ & $11(11)$ & $4(7)$ & 0.310 \\
\hline Smoking, n (\%) & $55(55)$ & $13(23)$ & $<0.0001$ \\
\hline \multicolumn{4}{|l|}{ Current medications } \\
\hline Antiplatelet agent, $\mathrm{n}(\%)$ & $2(2)$ & $11(19)$ & $<0.0001$ \\
\hline Acetylsalicylic acid, n (\%) & $15(15)$ & $19(32)$ & 0.008 \\
\hline Statins, n (\%) & $3(3)$ & $9(15)$ & 0.006 \\
\hline \multicolumn{4}{|l|}{ Laboratory findings } \\
\hline Low density lipoprotein cholesterol, $\mathrm{mg} / \mathrm{dL}$ & $108 \pm 37$ & $94 \pm 27$ & 0.011 \\
\hline High density lipoprotein cholesterol, mg/dL & $47 \pm 17$ & $44 \pm 12$ & 0.274 \\
\hline Hemoglobin A1c (\%) & $6.5 \pm 1.4$ & $6.6 \pm 1.1$ & 0.679 \\
\hline Creatinine, $\mathrm{mg} / \mathrm{dL}$ & $2.5 \pm 8.7$ & $1.1 \pm 0.5$ & 0.248 \\
\hline Estimated glomerular filtration rate, $\mathrm{mL} / \mathrm{min} / 1.7 \mathrm{~m}^{2}$ & $80 \pm 28$ & $76 \pm 23$ & 0.471 \\
\hline \multicolumn{4}{|l|}{ Angiography findings } \\
\hline Number of vessels with significant stenotic lesion & $1.3 \pm 0.6$ & $2.4 \pm 1.1$ & $<0.0001$ \\
\hline
\end{tabular}

Values are presented as mean \pm standard deviation or number (\%). STEMI, ST-segment elevation myocardial infarction; CTO, chronic total occlusion.

in other demographic and clinical characteristics.

\section{Cardiac and carotid artery ultrasonography findings}

The left ventricular ejection fraction were lower in STEMI patients, however there was no significant difference in low ejection fraction $(<45 \%)$ between the two groups. The left ventricular hypertrophy were higher in CTO patients, this result is associated with high systolic blood pressure of CTO patients. There were no significant differences in other cardiac ultrasonography findings. Carotid intima-media thickness was increased in CTO patients, and the proportion of patients with increased intima-media thickness $(>0.9 \mathrm{~mm})$ was higher. Also, although the prevalence of carotid artery plaque was similar between the two groups, number of plaques, the proportions of patients with multiple plaques $(\geq 3)$ and echogenic plaques were consistently higher in CTO patients. 
Cardiac and carotid artery ultrasonography findings of the studied patients were summarized in Table 2 and Fig. 3.

\section{Clinical outcomes}

All evaluated patients were followed up for at least 30 days, and the median follow-up duration was 27 (interquartile range: $16 \sim 47$ ) months. Over the entire follow-up duration, major adverse cardiovascular events newly occurred in 18 (32\%) CTO and $14(14 \%)$ STEMI patients $(P=0.008)$. Kaplan-Mayer survival curve for cumulative major adverse cardiovascular events were shown in Fig. 4. The non-fatal acute myocardial infarction newly occurred in $5(9 \%)$ CTO and $1(1 \%)$ STEMI patients $(P=0.013)$. However, there was no significant differences of newly developed all-cause death ( 4 vs. $2 \%, P=0.457$ ), non-fatal stroke ( 9 vs. $6 \%, P=$ 0.079 ), and repeated revascularization ( 5 vs. $5 \%, P=0.602$ ) in CTO and STEMI patients.

\section{DISCUSSION}

Carotid artery ultrasonography can provide important information to clinicians for the status of vascular atherosclerosis by the direct visualization of intima-media thickness or characteristics of atherosclerotic plaques. It is well known that, while increased intima-media thickness reflects early vascular atherosclerotic changes, the presence of plaques specifies more advanced status of vascular atherosclerosis. Clinical studies also reported that increased carotid intimamedia thickness with or without plaques was associated with the occurrences of cardiovascular or cerebrovascular events (O'Leary et al., 1999; Lorenz et al., 2007). However, the differences of carotid intima-media thickness and plaque

Table 2. Cardiac and carotid artery ultrasonography findings

\begin{tabular}{|c|c|c|c|}
\hline Unltrasonograhic parameters & $\begin{array}{c}\text { STEMI } \\
(\mathrm{n}=101)\end{array}$ & $\begin{array}{c}\text { CTO } \\
(n=57)\end{array}$ & $P$ \\
\hline \multicolumn{4}{|l|}{ Cardiac ultrasonography findings } \\
\hline Left ventricular ejection fraction, $\%$ & $50 \pm 10$ & $54 \pm 12$ & 0.034 \\
\hline Left ventricular ejection fraction $<45 \%, \mathrm{n}(\%)$ & $24(23)$ & $12(20)$ & 0.409 \\
\hline Left ventricular end-diastolic dimension, $\mathrm{mm}$ & $49 \pm 6$ & $51 \pm 6$ & 0.076 \\
\hline Left ventricular mass index, $\mathrm{g} / \mathrm{m}^{2}$ & $95 \pm 25$ & $101 \pm 25$ & 0.232 \\
\hline Left ventricular hypertrophy, $\mathrm{n}(\%)^{*}$ & $19(21)$ & $19(36)$ & 0.046 \\
\hline Mitral E/e' & $10.1 \pm 5.1$ & $9.8 \pm 3.5$ & 0.610 \\
\hline Diastolic dysfunction, $\mathrm{n}(\%)^{* *}$ & $8(9)$ & $2(4)$ & 0.222 \\
\hline \multicolumn{4}{|l|}{ Carotid ultrasonography findings } \\
\hline Carotid artery intima-media thickness, mm & $0.78 \pm 0.17$ & $0.97 \pm 0.13$ & $<0.0001$ \\
\hline Increased intima-media thickness, $\mathrm{n}(\%)^{* * *}$ & $33(33)$ & $48(84)$ & $<0.0001$ \\
\hline Presence of plaque, n $(\%)$ & $82(81)$ & $52(91)$ & 0.069 \\
\hline Number of plaques, $n$ & $1.7 \pm 1.2$ & $2.2 \pm 1.0$ & $<0.0001$ \\
\hline Number of plaques $\geq 3, \mathrm{n}(\%)$ & $34(34)$ & $31(54)$ & 0.030 \\
\hline Maximal diameter of plaque, $\mathrm{mm}$ & $2.3 \pm 1.0$ & $2.6 \pm 1.0$ & 0.073 \\
\hline Echogenic, n (\%) & $29(29)$ & $34(60)$ & 0.001 \\
\hline Echolucent, n (\%) & $53(65)$ & $18(32)$ & 0.001 \\
\hline
\end{tabular}

Values are presented as mean \pm standard deviation or number (\%). STEMI, ST-segment elevation myocardial infarction; CTO, chronic total occlusion.

*Left ventricular hypertrophy was defined as echocardiographically measured left ventricular mass index greater than $115 \mathrm{~g} / \mathrm{m}^{2}$ for males and $95 \mathrm{~g} / \mathrm{m}^{2}$ for females (Lang RM et al., 2005).

**Diastolic dysfunction was defined as echocardiographically measured mitral E/e' greater than 15 (Ommen SR et al., 2000$)$

***Increased carotid artery intima-media thickness was defined as echocardiographically measured intima-media thickness greater than $0.9 \mathrm{~mm}$ (Mancia G et al., 2007). 
(A)

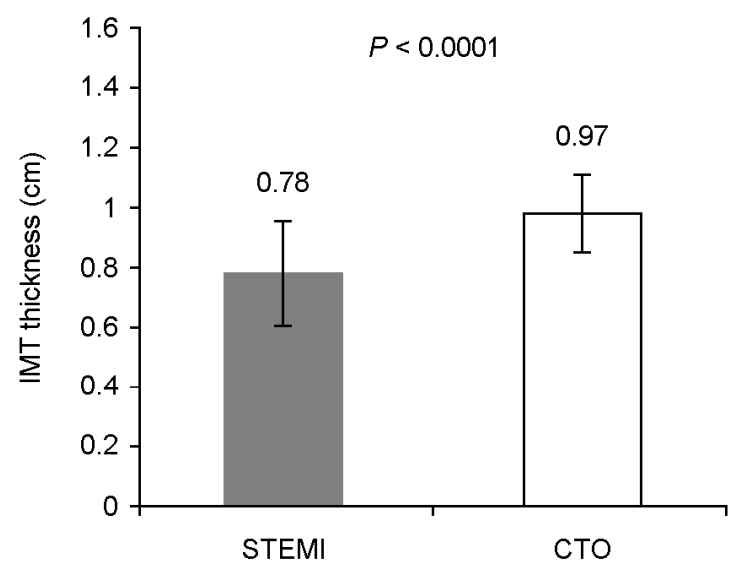

C

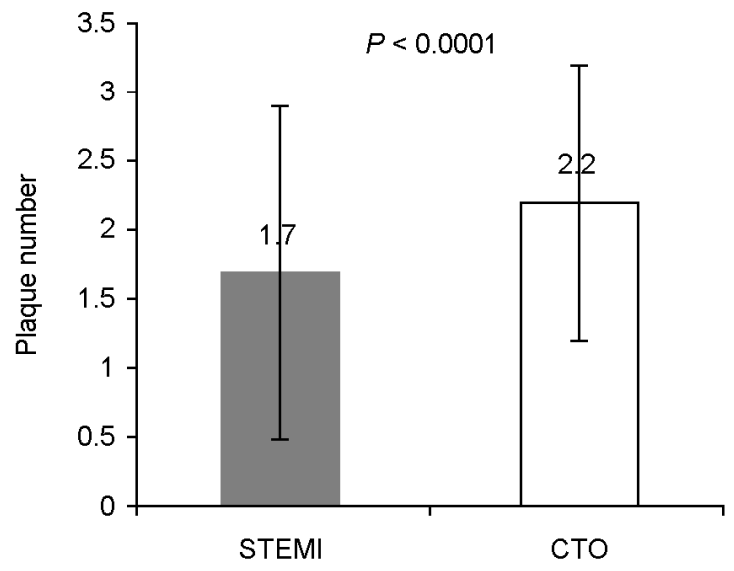

E

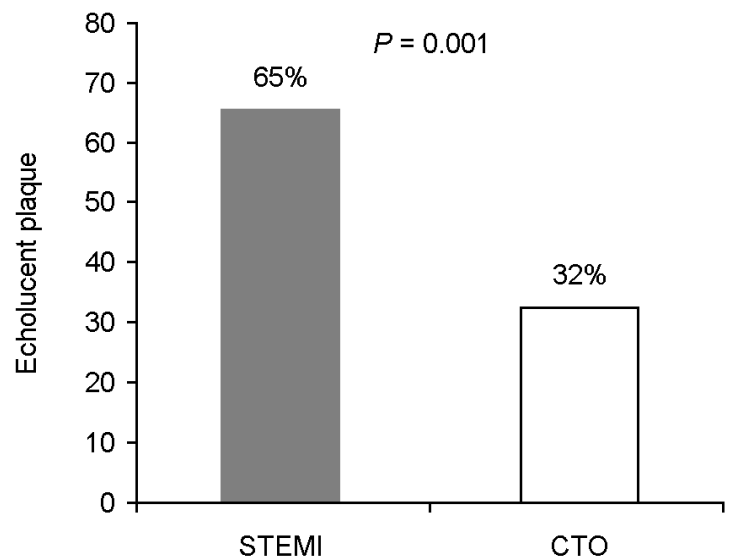

B

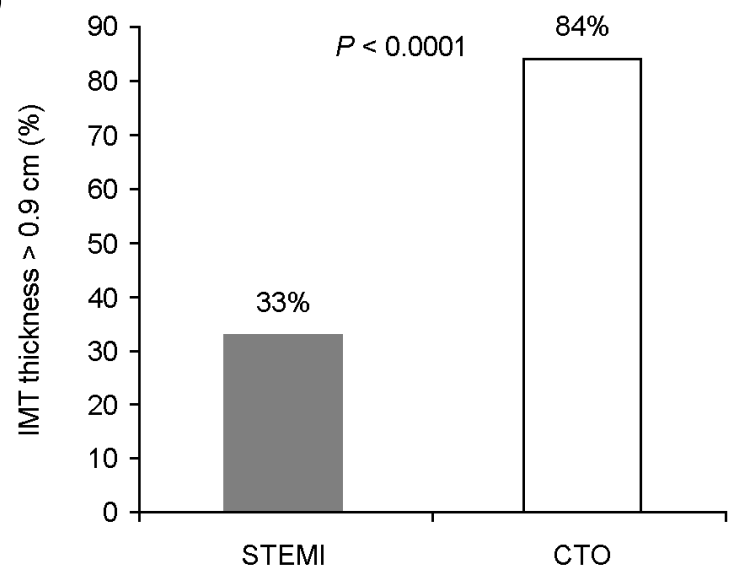

(D)

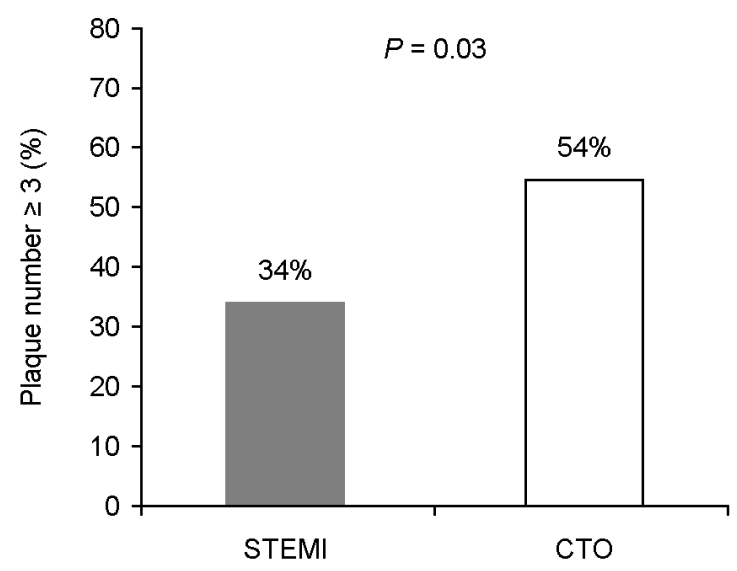

$\boldsymbol{F}$

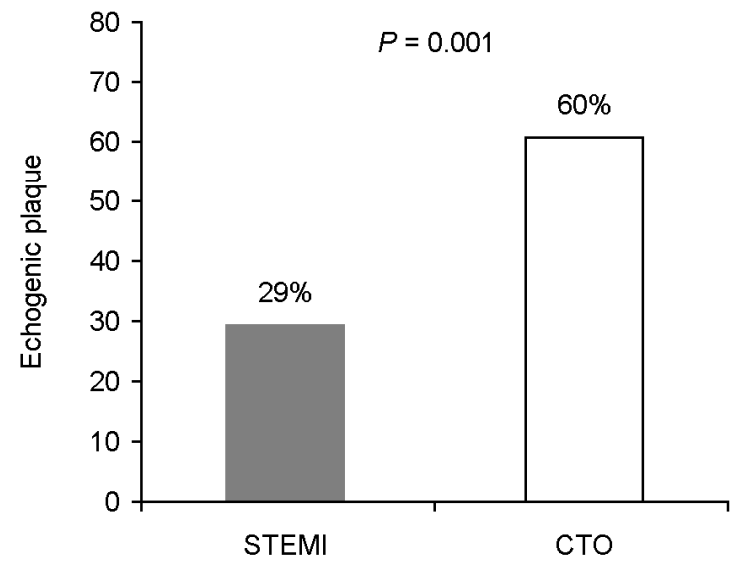

Fig. 3. The differences of carotid intima-media thickness and plaques between STEMI and CTO patients. (A) The carotid intima-media thickness was increased in CTO compared with STEMI patients. (B) The proportion of increased intima-media thickness $(>0.9 \mathrm{~mm})$ was also higher in CTO patients. (C) The numbers of total carotid plaques were more in CTO than STEMI patients. (D) The proportion of patients with multiple plaques (number $\geq 3$ ) was higher in CTO patients. (E and F) The proportion of patients with echolucent and echogenic plaques was higher in STEMI and CTO respectively. CTO, chronic total occlusion; STEMI, ST-segment elevation myocardial infarction; IMT, intimamedia thickness. 


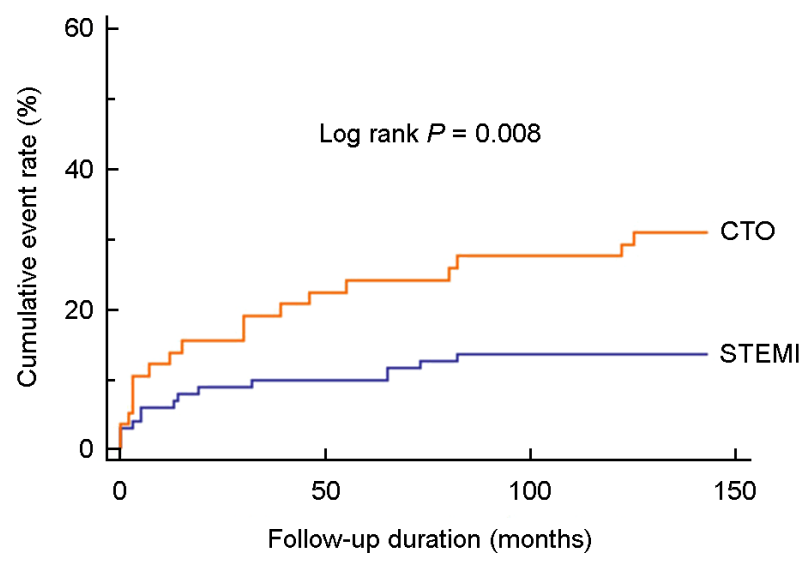

Fig. 4. Kaplan-Mayer analysis for major adverse cardiovascular events. During median follow up of 27 (interquartile range, 16 47) months, cumulative major adverse cardiovascular events defined as death of all causes, cerebral infarction, non-fatal acute myocardial infarction and repeated cardiac revascularization were higher in CTO patients. CTO, chronic total occlusion; STEMI, ST-segment elevation myocardial infarction.

characteristics between STEMI and CTO were not compared in previous studies.

In this study, we found that carotid intima-media thickness and plaque characteristics were significantly different between STEMI and CTO patients. Considering that the increased IMT was defined as $>0.9 \mathrm{~mm}$ (Mancia et al., 2007), the proportion of patients with increased intima-media thickness were significantly higher in CTO patients. Ultrasonographic characteristics of carotid artery plaques were also more complex in CTO patients. Numbers of plaques were greater, and multiple $(\geq 3)$ or calcified echogenic plaques were more commonly observed in CTO patients. In addition, as shown in Table 1, CTO patients were older and had more vascular atherosclerosis risk factors than STEMI patients. These findings suggest that, although CTO is regarded as a relatively benign coronary artery atherosclerotic disease when compared with STEMI, the burden of vascular atherosclerosis is much higher in CTO patients. In contrast, the proportions of patients with normal intimamedial thickness and non-calcified echolucent plaques were higher in STEMI. These findings suggest that, although STEMI is one of the most common fatal coronary artery atherosclerotic diseases, STEMI can develop in conditions without significant vascular atherosclerotic burden. In STEMI patients, the proportion of smoker and the level of low density lipoprotein cholesterol were also higher. It is well known that both smoking and increased low density lipoprotein cholesterol level are associated with the development of unstable atherosclerotic plaque, which can result in acute rupture and subsequent total occlusive thrombosis of coronary artery (Tsujita et al., 2010; Dohi et al., 2010).

Furthermore, we compared the incidences of newly developed major adverse cardiac events in STEMI and CTO patients. Although CTO is usually regarded as a relatively benign disease when compared with STEMI, overall major adverse cardiac events occurred more frequently in CTO patients during entire follow-up duration due to higher incidence of non-fatal acute myocardial infarction. Higher incidence non-fatal acute myocardial infarction in CTO patients can be explained by the higher numbers of diseased vessels and significant stenotic lesions documented by initial coronary angiography in these patients.

The present study has major limitations. First, because this is a single center for a limited number of patients who underwent carotid artery ultrasonography, the possibility of patient selection bias cannot be excluded, and the study results should not be generalized for all CTO and STEMI patients. Second, this is a cross-sectional study and therefore it is difficult to know the causal relationship between carotid artery atherosclerosis burdens and newly developed major adverse cardiac events. In addition, because this analysis was performed based on retrospective review of medical records, the completeness of data collection cannot be guaranteed. Therefore, the study results especially for clinical outcomes should be interpreted cautiously. So, further prospective studies with a large number of patients are necessary to clarify the differences of carotid ultrasonography findings and clinical outcomes between STEMI and CTO patients.

In conclusion, we found that carotid ultrasonography findings were significantly different between STEMI and CTO patients. The CTO patients had relatively higher carotid artery atherosclerosis burdens manifested as increased intimamedia thickness and complex plaque characteristics including echogenic plaques. In contrast, STEMI patients have 
relatively lower atherosclerosis burdens manifested by not increased intima-media thickness and echolucent plaques.

\section{Acknowledgements}

The study was supported by unrestricted Dong-A University Research Fund.

\section{Conflict of interest}

The authors have no potential conflict of interest to disclose.

\section{REFERENCES}

Amato M, Montorsi P, Ravani A, Oldani E, Galli S, Ravagnani PM, Tremoli E, Baldassarre D. Carotid intima-media thickness by B-mode ultrasound as surrogate of coronary atherosclerosis: correlation with quantitative coronary angiography and coronary intravascular ultrasound findings. Eur Heart J. 2007. 28: 2094 -2101 .

Aldridge ME, Do K, Oo T, Naqvi TZ. Carotid intima-media thickness and plaque assessment by trained medical residents: validation and preliminary testing of a training protocol. J Am Soc Echocardiogr. 2013. 26: 1457-1464.

Bots ML, Breslau PJ, Briët E, de Bruyn AM, van Vliet HH, van den Ouweland FA, de Jong PT, Hofman A, Grobbee DE. Cardiovascular determinants of carotid artery disease: the Rotterdam Elderly Study. Hypertension. 1992. 19: 717-720.

Belcaro G, Nicolaides AN, Laurora G, Cesarone MR, De Sanctis M, Incandela L, Barsotti A. Ultrasound morphology classification of the arterial wall and cardiovascular events in a 6-year follow-up study. Arterioscler Thromb Vasc Biol. 1996. 16: 851 $-856$.

Dohi T, Daida H. Change of concept and pathophysiology in acute coronary syndrome. Nihon Rinsho. 2010. 68: 592-596.

Heiss G, Sharett AR, Barnes R, Chambless LE, Szklo M, Alzola C, and the ARIC Investigators. Carotid atherosclerosis measured by B-mode ultrasound in populations: associations with cardiovascular risk factors in the ARIC study. Am J Epidemiol. 1991. 134: $250-256$

Hegele RA. The pathogenesis of atherosclerosis. Clin Chim Acta. 1996. 246: 21-38.

Johnsen SH, Mathiesen EB, Joakimsen O, Stensland E, Wilsgaard T, Løchen ML, Njølstad I, Arnesen E. Carotid atherosclerosis is a stronger predictor of myocardial infarction in women than in men: a 6-year follow-up study of 6226 persons: the Troms. Stroke. 2007. 38: 2873-2880.

Lorenz MW, Markus HS, Bots ML, Rosvall M, Sitzer M. Prediction of clinical CVEs with carotid intima-media thickness: a systematic review and meta-analysis. Circulation. 2007. 115: 459-467.

Lang RM, Bierig M, Devereux RB, Flachskampf FA, Foster E, Pellikka PA, Picard MH, Roman MJ, Seward J, Shanewise JS, Solomon SD, Spencer KT, Sutton MS, Stewart WJ; Chamber Quantification Writing Group; American Society of Echocardiography's Guidelines and Standards Committee; European Association of Echocardiography. Recommendations for chamber quantification. J Am Soc Echocardiogr. 2005. 18: 1440-1463.

Mannami T, Konishi M, Baba S, Nishi N, Terao A. Prevalence of asymptomatic carotid atherosclerotic lesions detected by highresolution ultrasonography and its relation to cardiovascular risk factors in the general population of a Japanese city: the Suita study. Stroke. 1997. 28: 518-525.

Mancia G, De Backer G, Dominiczak A, Cifkova R, Fagard R, Germano G, Grassi G, Heagerty AM, Kjeldsen SE, Laurent S, Narkiewicz K, Ruilope L, Rynkiewicz A, Schmieder RE, Boudier HA, Zanchetti A, Vahanian A, Camm J, De Caterina R, Dean V, Dickstein K, Filippatos G, Funck-Brentano C, Hellemans I, Kristensen SD, McGregor K, Sechtem U, Silber S, Tendera M, Widimsky P, Zamorano JL, Erdine S, Kiowski W, Agabiti-Rosei E, Ambrosioni E, Lindholm LH, Viigimaa M, Adamopoulos S, Agabiti-Rosei E, Ambrosioni E, Bertomeu V, Clement D, Erdine S, Farsang C, Gaita D, Lip G, Mallion JM, Manolis AJ, Nilsson PM, O'Brien E, Ponikowski P, Redon J, Ruschitzka F, Tamargo J, van Zwieten P, Waeber B, Williams B; Management of Arterial Hypertension of the European Society of Hypertension; European Society of Cardiology. 2007 Guidelines for the Management of Arterial Hypertension: The Task Force for the Management of Arterial Hypertension of the European Society of Hypertension (ESH) and of the European Society of Cardiology (ESC). J Hypertens. 2007. 25: $1105-1187$

O'Leary DH, Polak JF, Kronmal RA, Kittner SJ, Bond MG, Wolfson SK Jr, Bommer W, Price TR, Gardin JM, Savage PJ. Distribution and correlates of sonographically detected carotid artery disease in the Cardiovascular Health Study. Stroke. 1992. 23: 1752-1760.

O'Leary DH, Polak JF, Kronmal RA, Savage PJ, Borhani NO, Kittner SJ, Tracy R, Gardin JM, Price TR, Furberg CD. Thick- 
ening of the carotid wall. A marker for atherosclerosis in the elderly? Cardiovascular Health Study Collaborative Research Group. Stroke. 1996. 27: 224-231.

O'Leary DH, Polak JF, Kronmal RA, Manolio TA, Burke GL, Wolfson SK Jr. Carotid-artery intima and media thickness as a risk factor for myocardial infarction and stroke in older adults. Cardiovascular Health Study Collaborative Research Group. N Engl J Med. 1999. 340: 14-22.

Ommen SR1, Nishimura RA, Appleton CP, Miller FA, Oh JK, Redfield MM, Tajik AJ. Clinical utility of Doppler echocardiography and tissue Doppler imaging in the estimation of left ventricular filling pressures: a comparative simultaneous Doppler catheterization study. Circulation. 2000. 102: 1788 $-1794$.

Salonen R, Salonen JT. Determinants of carotid intima-media thickness: a population-based ultrasonography study in eastern Finnish men. J Intern Med. 1991. 229: 225-231.

Spence JD, Eliasziw M, DiCicco M, Hackam DG, Galil R, Lohmann

T. Carotid plaque area: a tool for targeting and evaluating vascular preventive therapy. Stroke. 2002. 33: 2916-2922.
Stone GW, Kandzari DE, Mehran R, Colombo A. Schwartz RS, Bailey S, Moussa I, Teirstein PS, Dangas G, Baim DS, Selmon M, Strauss BH, Tamai H, Suzuki T, Mitsudo K, Katoh O, Cox DA, Hoye A, Mintz GS, Grube E, Cannon LA, Reifart NJ, Reisman M, Abizaid A, Moses JW, Leon MB, Serruys PW. Percutaneous recanalization of chronically occluded coronary arteries: a consensus document: part I. Circulation. 2005. 112: 2364-2372.

Su TC, Jeng JS, Chien KL, Torng PL, Sung FC, Lee YT. Measurement reliability of common carotid artery intima-media thickness by ultrasonographic assessement. J Med Ultrasound. 1999. 7: 73-79.

Tsujita K, Kaikita K, Soejima H, Sugiyama S, Ogawa H. Acute coronary syndrome-initiating factors. Nihon Rinsho. 2010. 68: 607-614.

Wendelhag I, Olov G, Wikstrand J. Arterial wall thickness in familial hypercholesterolemia: ultrasound measurement of intima-media thickness in the common carotid artery. Arterioscler Thromb. 1992. 12: 70-77. 